\title{
Eating Disorders throughout Female Adolescence
}

\author{
F. Dominé · C. Dadoumont · J.-P Bourguignon \\ Service de Pédiatrie, CHU de Liège, Chênée, Belgium
}

\begin{abstract}
Eating disorders (EDs) are conditions which are becoming more and more widespread among adolescents and they often lead them to seek the opinion of a professional health caregiver, including gynecologists and pediatricians. EDs, and particularly anorexia nervosa (AN), are usually classified as psychological or psychiatric disorders, but they may have major somatic implications and complications as osteoporosis, nutritional deficiencies, cerebral atrophy, cardiac and metabolic disorders. A key issue in the management is prevention or reduction of both the serious somatic consequences and the important mental health consequences (e.g. depression, psychosocial withdrawal, phobia and suicide), integrating different perspectives (psychological or psychiatric - individual and familial -, genetic, nutritional, pediatric, gynecological). Adolescence is a critical period for the onset of EDs though they may also involve younger children. In this case, the consequences on the development (height, weight, puberty) can also be significant. In this review, we will focus on eating disorders in adolescent girls with an emphasis on AN. We describe variations in ED characteristics and their management depending on age at occurrence. A possible ED should be considered by pediatricians consulted about delayed female growth and puberty as well as gynecologists in patients with primary or secondary amenorrhea or infertility.
\end{abstract}

Eating disorders (EDs) represent, beyond asthma and obesity, conditions leading more and more adolescents to seek the opinion of a professional health caregiver, including gynecologists and pediatricians [1]. Though it is commonly agreed that EDs are much more frequent in girls, a recent study based on a self-administered and anonymous questionnaire showed that $50 \%$ of boys aged 16-20 years expressed concern about their weight and body image and almost $20 \%$ were involved in some disturbed eating behaviors [2]. While EDs, particularly anorexia nervosa (AN) are usually classified as psychological or psychiatric disorders, they may have major somatic implications on account of several reasons. The weight changes (loss or gain) due to impaired energy balance, the deficits in specific dietary components and the weight control methods set up by those young people, such as purgative behaviors, may compromise health. In addition, AN involves alterations of homeostatic processes that may have somatic consequences independent of weight or nutritional changes. A key issue in the management is prevention or reduction of both the disastrous mental health consequences of EDs (e.g. depression, psychosocial withdrawal, phobia and suicide) and the serious somatic consequences (e.g. osteoporosis, obesity or nutritional deficiencies, cerebral atrophy, cardiac and metabolic disorders).

Because EDs result from a complex and still elusive pathogenesis and are more or less resistant to management strategies irrespective of the discipline, they are challenging the patients, the families and beyond them the clinicians and the scientists, despite efforts reflected in the abundant literature about this topic. Consistent with this, the management of EDs requires integration of different perspectives (psychological or psychiatric individual and familial -, genetic, nutritional, pediatric, gynecological) in an attempt to maximize support to the patient and the family.

Adolescence is a critical period for the onset of eating disorders. Puberty involves profound endocrine and physical changes together with psychic and cognitive remodeling and underlying CNS structural modifications [3]. Understandably, the profound physical and mental changes challenging normal adolescents together with social models idealizing thinness in young people can account for increased susceptibility to develop body shape concerns and EDs at the time of adolescence. In the USA, two thirds of adolescent girls were found to worry about remaining/becoming thin [4]. More recently, it appeared that, among adolescent girls, above 55\% were involved in unhealthy weight control methods such as laxative abuse, self-induced vomiting, severe food restriction, fasting, draconian diet [5].

In this review, we will focus on eating disorders in adolescent girls with an emphasis on AN. This condition is of particular interest for pediatricians who may be consulted about disorders of growth and puberty as well as gynecologist who see those patients because of primary or secondary amenorrhea or infertility. Importantly, however, a variety of health care providers including dieticians and psychologists may be first consulted by patients with EDs and have each to introduce the patient to interdisciplinary management as a crucial issue. 


\section{Definition and Diagnostic Criteria: Eating Disorders versus Disordered Eating}

The conditions classically evoked as EDs are AN and bulimia nervosa (BN). These two major disorders, also called 'full ED' meet diagnostic criteria that are listed in DSM-IV manual of the American Psychiatric Association [5] and summarized in table 1. Diagnostic criteria stated slightly differently were proposed in the International Classification of Diseases (ICD) established by the WHO [7]. For comparison purposes, they are also listed in table 1. Though AN and BN might be seen as opposing conditions, they share common characteristics including pursuit of thinness, fear of weight gain, and cognitive overinvestment of everything that refers to food. Quite frequently, anorectic girls fear becoming bulimic and bulimic girls hope for becoming anorectic. Forty to $50 \%$ of patients with AN develop BN after months or years [8].

The current concept is to consider, besides AN and BN, the eating disorders not otherwise specified (EDNOS), also called 'partial or atypical ED' (table 1). The EDNOS may be more frequent than AN and BN, clustering the large family of disturbed behaviors in relation with feeding. Obviously, there are no unequivocal criteria defining EDNOS since those disorders include any condition that does not strictly meet the criteria of AN or BN. As illustrated schematically in figure 1, the EDNOS are currently viewed as an intermediate condition between simply dieting and full EDs [1]. Partial EDs are often impermanent and spontaneously resolving but evolution through full ED is possible [9]. The adolescents involved in strict dieting in order to lose weight are more likely to develop a full ED within one to three years [10]. In a study involving 16-year-old girls with a partial ED, $7 \%$ developed full ED subsequently [11]. The earlier treatment is initiated, the better is prognosis since the risk of developing a more complicated and persisting disorder is reduced [1]. Therefore, prevention, screening and early management of EDNOS is recommended instead of a 'wait and see option [12].

In the clinical setting, the diagnosis of AN lies on a triad: anorexia, weight loss and amenorrhea. Anorexia is a self-imposed severe restriction of food intake, hunger being thus effective but controlled. The symptom of anorexia is frequently rationalized by the patient who provides explanations such as dysfunction of digestion or food intolerance. Somatic complaints centered on the abdomen and digestion, are commonly associated. Purgative conducts (self-induced vomiting, laxative abuse, compulsive exercises) can also be associated. A potomania is often present in the daytime.

Weight loss occurs more or less rapidly with the disease. In a still growing patient, drawing the height, weight and BMI curve is very informative as illustrated in figure 2. In a post-pubertal adolescent girl, 18 is the BMI limit of thinness. Since restriction of food intake and weight loss may be denied by the patient or underestimated due to distortion of self-image, it is important to evaluate additional signs of undernutrition including alterations of nails, hair and skin, reduced blood flow at extremities. The patient denial of thinness is fundamental for diagnosis of EDs because weight loss is acknowledged by the patient when caused by underlying somatic diseases or planned weight management in the case of dancers or gymnasts. While it is important that the patient is provided with a realistic evaluation of weight deficit and the related concerns, the physician should also express his/her awareness of the patient distortion of self-image. A BMI level considered to be life-threatening is <14 and hospital admission may be required. However, these limits need some adjustment taking into account factors such as rapidity of weight loss, mental health and neurological functioning. The mortality risk increases dramatically when BMI falls to $<11$.

Fig. 1. Schematic representation of the interconnections between the three forms of eating disorders, some predisposing conditions and pathogenetic factors.

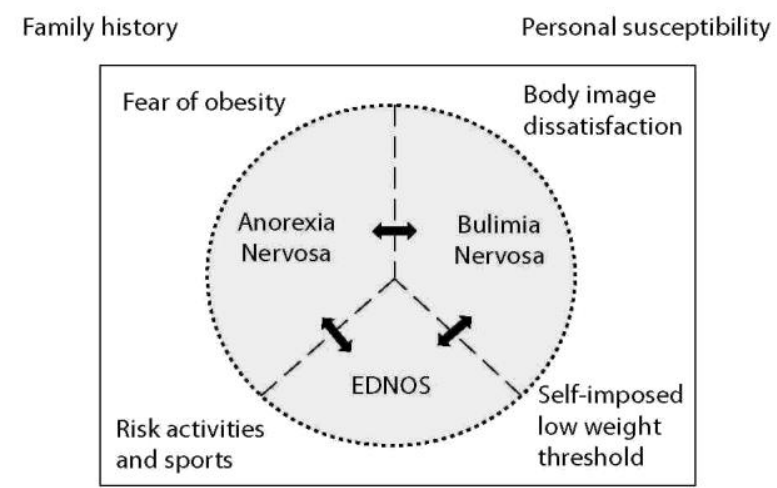


Table 1. Criteria of eating disorders according to DSM IV-R* and IDC of WHO**

\begin{tabular}{|c|c|}
\hline Anorexia nervosa & Bulimia nervosa \\
\hline Voluntary food intake limitation.* & \\
\hline $\begin{array}{l}\text { Weight loss self-induced by avoidance } \\
\text { of 'fattening foods' and one or more of } \\
\text { the following: self-induced vomiting; } \\
\text { self-induced purging; excessive } \\
\text { exercise; use of appetite suppressants } \\
\text { and/or diuretics. } * *\end{array}$ & $\begin{array}{l}\text { Eating, in a discrete period of time (e.g. } \\
\text { within any 2-hour period), an amount of } \\
\text { food that is definitely larger than most } \\
\text { people would eat during a similar period c } \\
\text { time and under similar circumstances.* }\end{array}$ \\
\hline $\begin{array}{l}\text { Refusal to maintain body weight at or } \\
\text { above a minimally normal weight for } \\
\text { age and height (e.g. weight loss leading } \\
\text { to maintenance of body weight less than }\end{array}$ & $\begin{array}{l}\text { A sense of lack of contr } \\
\text { during the episode (e.g. } \\
\text { cannot stop eating or co } \\
\text { much one is eating). } *\end{array}$ \\
\hline $\begin{array}{l}85 \% \text { of that expected; or failure to make } \\
\text { expected weight gain during period of } \\
\text { growth, leading to body weight less than }\end{array}$ & $\begin{array}{l}\text { Persistent preoccupation with eating, and } \\
\text { an irresistible craving for food.** }\end{array}$ \\
\hline $85 \%$ of that expected). ${ }^{\prime \prime} * *$ & \\
\hline BMI 17.5 or less.** & $\begin{array}{l}\text { behavior in order to prevent weight gain, } \\
\text { such as self-induced vomiting, misuse of }\end{array}$ \\
\hline $\begin{array}{l}\text { Intense fear of gaining weight or } \\
\text { becoming fat, even though } \\
\text { underweight* }\end{array}$ & $\begin{array}{l}\text { laxatives, diuretics, enemas, or other } \\
\text { medications; fasting, or excessive } \\
\text { exercise.* }\end{array}$ \\
\hline
\end{tabular}

\section{EDNOS}

Eating disorders not otherwise specified include disorders of eating that do not meet the criteria for any specific eating disorder (AN or $\mathrm{BN}) . * * *$

(1) In female patients, all the criteria for anorexia nervosa met except that menses are regular.*

(2) All the criteria for anorexia nervosa met except that, despite significant weight loss, the patient's current weight is in the normal range.*

(3) All the criteria for bulimia nervosa met except that the binge eating and inappropriate compensatory

Other compensatory behaviors: alternating mechanisms occur less than periods of starvation; use of drugs such as twice a week or for less than 3 appetite suppressants, thyroid preparations.**

When bulimia occurs in diabetic patients they may choose to neglect their insulin treatment.** The binge eating and inappropriate compensatory behaviors Body-image distortion in the form of
specific psychopathology whereby a dread of fatness persists as an intrusive, occur, on average, at least twice a week for overvalued idea and the patient imposes 3 months.* months.*

(4) Normal body weight and regular use of inappropriate compensatory behavior after eating small amounts of food (e.g. self-induced vomiting after consuming two cookies).*

Self-evaluation unduly influenced by body shape and weight*

Amenorrhea: In postmenarcheal females, absence of at least three consecutive menstrual cycles.*

Widespread endocrine disorder involving the

hypothalamic-pituitary-gonadal axis manifested in women as amenorrhea (without replacement or contraceptive pill) and in men as a loss of sexual interest and potency. Possibly elevated levels of growth hormone and cortisol, changes in the peripheral metabolism of the thyroid hormones and abnormalities of insulin secretion.**

Absence of preexisting psychiatric disease.*

The disturbance does not occur exclusively during episodes of anorexia nervosa.*

The psychopathology consists of a morbid dread of fatness and the patient sets herself or himself a sharply defined weight threshold, well below the premorbid weight that constitutes the optimum or healthy weight in the opinion of the physician. There is often, but not always, a history of an earlier episode of anorexia nervosa, the interval between the two disorders ranging from a few months to several years. This earlier episode may have been fully expressed, or may have assumed a minor cryptic form with a moderate loss of weight and/ora transient phase of amenorrhea.**

Types: restricting vs. binge-eating/ purging*
(5) Repeatedly chewing and spitting out, but not swallowing, large amounts of food.*

Binge eating disorder: recurrent episodes of binge eating in the absence if regular inappropriate compensatory behavior characteristic of bulimia nervosa.*
Types: purging vs. nonpurging (exercise and fasting to compensate). 
Fig. 2. Changes in height, weight and BMI in a premenarcheal adolescent girl developing AN at 10 years of age. Noteworthy, height velocity is reduced and weight loss is more obvious from the BMI curve than the weight curve.
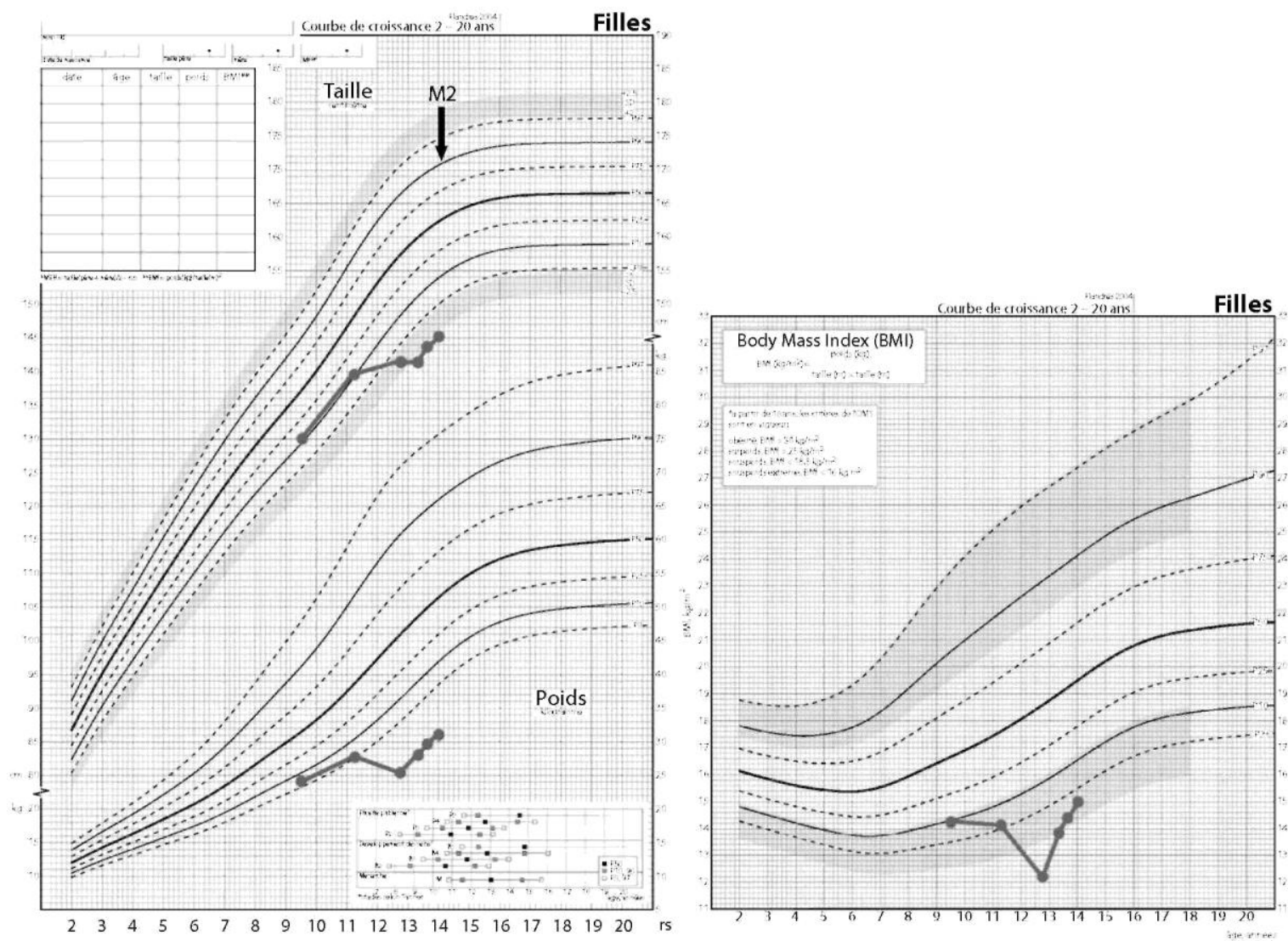

Amenorrhea is defined as absence of menstruations during 3 or 6 consecutive months when the cycles were previously regular or irregular, respectively. Amenorrhea can occur after, together with or even before weight loss. This observation suggests that negative energy balance secondary to weight loss is not or not always the determinant of amenorrhea that could involve other mechanisms (see below).

Beyond the interconnections between the three forms of eating disorders (AN, BN, EDNOS), they can be integrated into in a larger group of more frequent disturbed eating behaviors that are linked through time and mechanisms (fig. 1). Accordingly, similar factors can predict or cause any of those minor or major forms of EDs.

Weight status can be an indication of the underlying form of ED since obesity is common in compulsive browsing and binge eating and leanness in restrictive or purgative AN [13]. Normal BMI is common in bulimic patients, irrespective of purging conducts. Among patients with a similar form of ED, however, weight or BMI can be highly variable and changes can occur in short periods of time. Thus, a normalized weight does neither justify that a previous diagnosis of ED is reconsidered nor represent a positive prognostic factor. Though adverse health effects appear to be less obvious in ED patients with normal weight, such patients may be involved in harmful conducts, like purgative behaviors, that can be pernicious because more difficult to diagnose and to treat.

\section{Epidemiology}

Because EDs are consistent with several more or less precisely defined clinical conditions, their prevalence is not easy to determine. As far as AN in late adolescent and young adult females is concerned, a prevalence of $0.5-1 \%$ is usually mentioned [14]. The incidence appears to be different among studies: 1-12/100,000/year [14]. It seemed to have increased during the 1980s with no further increase currently [8]. The mean age of occurrence of AN is around 17, between 15 and 19 years [14]. Some later forms of AN start in adulthood though they are rather consistent with the adult emergence of a latent eating disorder existing since childhood or adolescence. 


\section{Pathogenesis, Homeostatic Disturbances}

\section{Pathogenesis of EDs}

Despite abundant literature, the etiology of EDs remains complex and obscure. Several factors have been proposed (psychiatric, genetic, neurophysiological, psychosocial, etc.) and it is agreed that there is not any single explanation or mechanism accounting for EDs. Rather, most authors consider that several additive or synergistic factors lead a patient to develop an ED though it is unclear which among those factors account for either predisposition to the disease or onset, aggravation or persistence. This is consistent with bio-psycho-social models.

Genetic and neurobiological factors are likely to play a role as suggested by family clustering of AN or other disorders. This prompted several authors to search for gene polymorphism or other anomalies but not any single gene has been identified so far. While genes related to serotonin synthesis, transport and metabolism appear to be involved in several studies, the current concept is a polygenic determinism. Since estrogens are known to promote the expression of different genes, such a mechanism could explain the increasing incidence of EDs at the time of puberty [15]. Neurobiological mechanisms could explain, for instance, distortion of self-image that has been associated with parietal cortex dysfunction [16]. Studies including imaging of the CNS demonstrated the possible involvement of neuropeptides or neurotransmitters, with emphasis on serotonin. For instance, Audenaert et al. [17] showed a specific regional reduction in binding capacity of the 5-HT2a receptors in low-weight AN patients compared with healthy volunteers. In addition, a physiologic response to the administration of serotonin agonists can be observed in low-weight AN patients [18]. A genetic origin of such serotonin dysregulation could also explain family susceptibility to AN, as suggested by twin and family studies [19]. Based on those data, some authors proposed serotonin supplementation in AN [20, 21].

Psychosocial factors are also probably involved. Adolescence is a critical period regarding not only physical changes, but also psychological and cognitive turmoil both individually and versus peers and family [9]. Corporal changes require adaptation, but may also lead to some distortion of body self-perception, frequently resulting in self-devaluation or low self-esteem [22, 23]. Body image is known to be a crucial factor predicting involvement in dieting, which may in turn sink into disturbed eating behaviors [5, 10, 24-26]. Some factors related to social environment were shown to be associated with EDs: problematic interpersonal connectedness at school, peer mobbing or teasing, and social, media or even medical pressure on weight control [25]. Sometimes, a single physician criticism at medical exam can leave a mark on an adolescent and induce some weight concerns. Factors related to family life conditions are also associated with EDs: parental couple conflicts, history of sexual or physical abuse [27], parental obesity or history of dieting or anorexia [24].

Hormonal factors include the hormonal storm of puberty and the effects of deviations in pubertal timing. The link between pubertal timing and EDs remains controversial [28]. While early puberty does not seem to influence body satisfaction or involvement in dieting, a slight but significant association was found with occurrence of EDs [28, 29]. In a recent study, however, girls self-rated as early or late maturers were both significantly more likely to present disturbed eating behaviors [30].

Professional or sport practices sometimes involve strict weight control and make subjects more susceptible to EDs: fashion, esthetician, gymnast, athletes, dancer. . . [31].

Personality characteristics or psychiatric factors were shown to be predictive of AN: perfectionism, high sensitivity, empathy, competitiveness and difficulty in setting limits. Dysthymia, depression, suicidal thoughts, self-aggressiveness, obsessional compulsive disorder or borderline personality are often associated with eating disorder [1,4, 32-35].

\section{Pathogenesis of Amenorrhea}

The functional integrity of the hypothalamic-pituitary-ovarian axis is dependent on energy availability as shown in dancers who are regularly cycling or amenorrheic depending on normal or reduced BMI, irrespective of physical activity [36]. Such a mechanism may contribute to the pathogenesis of amenorrhea in AN, as illustrated in figure 3 a. Then, reduced fat mass and consequently reduced leptin is a key mechanism since the facilitatory role of leptin on the hypothalamic control of reproductive system is well established [37]. Leptin can be a final mediator independently of fat mass since recombinant leptin therapy for up to 3 months in women with hypothalamic amenorrhea restored pituitary-ovarian activity and menstrual cyclicity despite concomitant reduction in weight and fat mass [38]. Only one third of anorectic patients however start amenorrhea after a significant weight loss whereas half of them show amenorrhea from the time of onset of dieting and one sixth before [39], suggesting another mechanism (fig. 3b). It can be hypothesized that estrogen deprivation resulting from arrested pituitary ovarian activity account for the loss of the many neurobiological effects of the steroid and play some pathogenetic role. However, there is no evidence so far that estrogen replacement has any effect on the outcome of the disease 
though this has not been systematically studied. The time differences between onset of amenorrhea and weight loss could reflect different pathogenetic mechanisms and could explain heterogeneity in clinical presentation of the disorder.

We studied retrospectively the temporal dissociation between amenorrhea and weight loss in adolescent girls seen for EDs in our Pediatric Endocrinology/ Adolescent Medicine Unit. Forty-eight percent of them presented amenorrhea before or at the beginning of weight loss. Such precocity of amenorrhea was related to higher initial weight loss, lower BMI at first visit, and preponderant in the restrictive form of ED. The persistence of menstruations was related to lower initial weight loss, higher BMI at first visit and preponderant in the purgative form of ED. The severity of ED, as reflected by several clinical parameters (weight loss velocity, duration of weight loss, lowest BMI observed, etc.), was related to the rapidity of occurrence of amenorrhea, suggesting the involvement of impaired neuroendocrine mechanisms related to disordered homeostasis, independently of energy imbalance.

Fig. 3. Two possible mechanisms for pathogenesis of amenorrhea in anorexia nervosa.

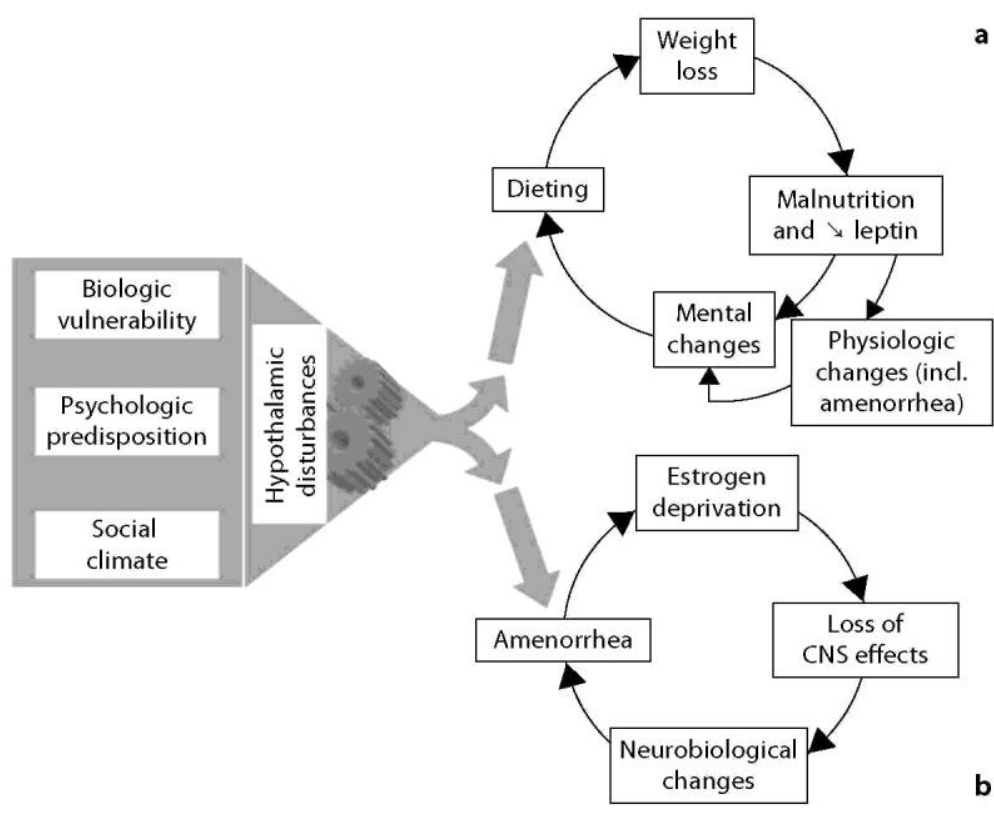

\section{Variations in ED Characteristics Depending on Age at Occurrence}

In table 2 are summarized features of $\mathrm{AN}$ in relation to developmental stage at occurrence of the disease. As detailed in the chapter by Bourguignon and Juul [this vol.], pubic hair development in females can involve adrenal androgens that are not dependent on pituitary-ovarian activity. Thus, pubic hair could develop in an ED patient despite pituitary-ovarian inhibition.

In prepubertal premenarcheal girls, breast development can be absent or just starting. However, because initiation of the pubertal growth spurt is in fact the first clinical event of female puberty, growth stunting can be an important feature. The mechanism is complex, involving lack of energy intake and deficiency in specific nutrients (calcium, vitamin D, etc.). Among the endocrine factors, estrogen deprivation but also reduction of insulin-like growth factor-1 secretion can play a role. Recovery from AN can be associated with some increase in height velocity though a spurt comparable with that occurring physiologically is unlikely. This is because increase in age accounts normally for progressive reduction of the magnitude of the spurt and also because normalization of dietary intake, neuroendocrine and psychosocial functioning in $\mathrm{AN}$ is a slow and often partial process. The highest risk of insufficient bone mineralization and subsequent fractures can be observed in those conditions since peak bone mass is achieved during the pubertal growth spurt. Osteopenia can occur as early as after 6 months and justifies osteodensitometry to be performed in the 1st year of the disease. While osteopenia can persist for a long time [40] and is observed in $90 \%$ of AN, it can also be found in patients with EDNOS [41]. The mechanisms of osteopenia are similar to those of stunted growth. In addition, hypoleptinemia and hypercortisolism could play some role as well. Moreover, prognosis is less favorable with increased risk of chronic forms when eating disorders appear early, before puberty [42]. Further difficulties and delay in the management come from the frequent denial 
involving the patient, the parents and even the physician.

In pubertal premenarcheal girls, breast development has more or less occurred but is difficult to evaluate clinically due to weight loss resulting in reduced breast size. Time elapsed between onset of breast development and first clinical evidence of ED (for instance start of weight loss or altered feeding behavior) can be informative since the average interval between onset of breast and first menses is around 2 years. Due to the precocity of growth acceleration in female puberty, growth impairment in these conditions is often less than in earlier forms of EDs.

In postpubertal postmenarcheal girls, amenorrhea is secondary and breast size should have regressed after having been completed. These patients can be opposed to the very early forms since they should have experienced almost fully mature body image and functioning before starting an ED. Since about $95 \%$ of adult height is attained at the time of menarche, the consequences for growth are usually not a relevant matter of concern in such patients. However, bone mineralization can still be impaired in these conditions and warrants evaluation and management. Rationalization capacity is commonly greater in these patients with less denial.

Table 2. Some characteristics of AN patients in relation to developmental stage at diagnosis

\begin{tabular}{|c|c|c|}
\hline Prepubertal & Pubertal & Postpubertal \\
\hline Premenarcheal & & Postmenarcheal \\
\hline Primary amenorrhea & Primary amenorrhea & Secondary amenorrhea \\
\hline Stunted growth & $\begin{array}{l}\text { Stunted growth, reduced growth } \\
\text { spurt }\end{array}$ & Final height (almost) attained \\
\hline Absent puberty & Arrested puberty & Finalized puberty \\
\hline No breast development & Partial breast development & Reduced breast size \\
\hline Denial ++ & Denial ++ & Denial $+/-$ \\
\hline Peak bone mass not achieved & Peak bone mass not achieved & $\begin{array}{l}\text { Peak bone mass achieved } \\
\text { Loss in bone density }\end{array}$ \\
\hline Lower rate of full recovery & $1 / 3$ fully recovered, $1 / 3$ partially & recovered, $1 / 3$ chronic \\
\hline
\end{tabular}

\section{Out-Patient vs. In-Patient Management of the Adolescent Patient with ED}

In this review, we elect to discuss several somatic manifestations of EDs and address the issue whether management is possible on an out-patient basis or requires referral to an in-patient unit and based on which criteria (table 3). A prerequisite to therapy is that a diagnosis has been made as clear as possible and communicated to the patient and the close relatives. It is crucial that EDs are identified and presented as serious diseases having no single causes and overriding rational explanations and solutions. It is generally agreed that no univocal treatment does exist and that multidisciplinary management plus time are required for improvement [43].

Weight loss does usually not respond to dietary recommendations or even strict guidelines. Its management is indirect through weight limits assigned to the patient for consideration of hospital admission. The significance of the weight limit is protection against a condition that could or would become life-threatening. Weight gain objectives can also be assigned in a given period of time (weeks). Though indicative values of weight and BMI limits are given in table 3, they deserve integration with the other somatic and psychiatric components and their changes over time. In patients with weight loss exceeding $20 \%$, refeeding must be very progressive with a supplementation in mineral nutrients because of the risk of refeeding syndrome. This involves metabolic disturbances (hypophosphoremia, hypomagnesemia, hypokalemia, hypocalcemia and hypoglycemia) and may cause a potentially lethal multivisceral failure. The daily energy intake should start with $500 \mathrm{kcal}$ and increase to 1,500 within a week of time. Initial water intake should be also limited to $500 \mathrm{ml} /$ day [44, 45].

Arrested puberty and amenorrhea would require estrogen alone or associated with progestin depending on the developmental stage attained. Sex steroid administration in EDs is controversial. Reappearance or occurrence of menstruations could be badly accepted by patients denying femininity and warrants open discussion with the patient before being initiated. An indication of hormonal therapy is contraception even in amenorrheic adolescents who could be sexually active. In other instances, there is no consensus about the duration of amenorrhea before 
treatment is proposed to the patient. Such proposal seems reasonable after 1 year of follow-up, even more when amenorrhea persists despite weight regain [44].

As discussed above, osteopenia is multifactorial and cannot be prevented by a single treatment. Because nutritional deficiency is likely a most important factor that requires a long time before getting back to normal conditions, supplementation with calcium and vitamin $\mathrm{D}$ is systematic. The effects of estrogen substitution are not convincing as discussed above. In patients with severe bone demineralization accounting for fractures and risk of neurological consequences when the spine is involved, biphosphonates and in-patient management should be considered.

Metabolic disturbances deserve some comments since they are especially frequent in the patients with purgative behaviors like vomiting or laxative abuse. Discrete early signs of such behaviors can be detected: dry or scaly skin, melanodermia, breakable nails, hair loss; callus at the metacarpo-phalangeal articulations of second and third fingers due to iterative frictions during induction of vomiting; tongue inflammation and/or salivary glands hypertrophy (especially parotid gland) due to frequent compulsive binge eating. Some biological disturbances can also be found, relatively specific of AN (table 3). Severe complications involve gastrointestinal tract such as Mallory-Weiss syndrome as well as other functions such as cardiac arrhythmia secondary to electrolyte anomalies.

\section{The Lean Exercising Adolescent}

Both AN patients with hyperactive behavior and some adolescent girls involved in strenuous physical activity share amenorrhea, leanness and exercising as common features. Menstrual disturbances can involve close to $25 \%$ of lean sportive adolescent, depending on type, duration and intensity of activity as well as nutritional status [46].

In addition, biological stigmata may show similar alterations in both conditions such as hypercortisolism. This finding is consistent with chronic stress condition either physically or mentally or both. It is, however, difficult to evaluate the pathogenetic role of stress in the occurrence and the persistence of dysfunction of the energy balance and the reproductive system in those patients. In table 4 are summarized some features helping in the differentiation between adolescent girls with AN and female amenorrheic athletes. It should be noted that some subjects initially involved in strenuous physical activity can secondarily develop typical ED such as AN. Interestingly, it appears that estro-progestin treatment in female athletes result in increase in body weight and bone mineralization without affecting physical performances [47]. This is in contrast with studies in AN patients showing that use of contraceptive doses of estro-progestin does not significantly increase bone mineralization [48, 49].

Table 3. Somatic aspects in the management of anorexia nervosa

\begin{tabular}{lll}
$\begin{array}{l}\text { Clinical manifestations or } \\
\text { complications }\end{array}$ & Out-patient management & $\begin{array}{l}\text { Criteria for in-patient } \\
\text { admission }\end{array}$ \\
\hline Weight loss & Increase energy intake & $\begin{array}{l}\text { Cachexia, weight falling below } \\
35 \% \text { of normal weight for height } \\
\text { orBMI }<14\end{array}$ \\
\hline
\end{tabular}

Arrested puberty (and growth) Estrogen or estroprogestative replacement; Amenorrhea primary, secondary after 6-12 months' evolution?

\begin{tabular}{lll}
\hline Osteopenia & $\begin{array}{l}\text { Calcium 1,000-1,500 mg/day Vitamin D } \\
\text { min 800 U/day Estro-progestative? } \\
\text { Biphosphonates? }\end{array}$ & $\begin{array}{l}\text { Vertebrae compression Bone } \\
\text { fracture }\end{array}$ \\
\hline $\begin{array}{l}\text { Dental enamel erosion due to } \\
\text { iterative vomiting }\end{array}$ & $\begin{array}{l}\text { Mouth rinsing with clear water Teeth } \\
\text { brushing >20 min after vomiting }\end{array}$ \\
\hline Pyrosis -esophagitis -gastritis & $\begin{array}{l}\text { Antiemetics Ranitidine Omeprazole Gastric Mallory-Weiss syndrome } \\
\text { plaster }\end{array}$ & $\begin{array}{l}\text { Superior mesenteric artery } \\
\text { syndrome }\end{array}$ \\
\hline
\end{tabular}




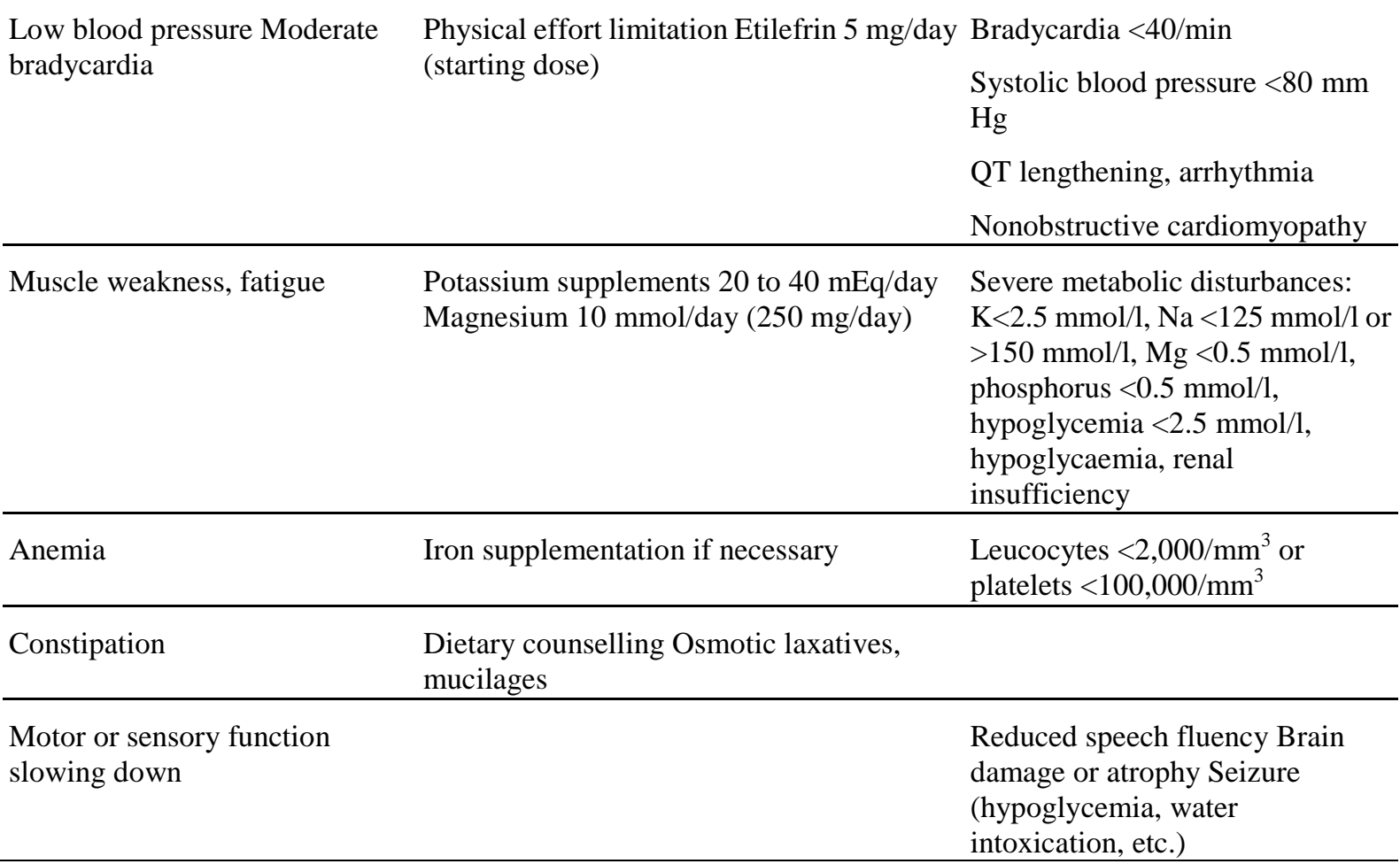

Table 4. Comparative features of AN and sportive lean adolescent girls with similar BMIs

\begin{tabular}{lll}
\hline & $\begin{array}{l}\text { AN patient investing physical } \\
\text { activity }\end{array}$ & $\begin{array}{l}\text { Strenuously sportive lean } \\
\text { adolescent girl }\end{array}$ \\
\hline Physical activity & compulsive, restless, permanent & programmed training, competition \\
\hline Energy intake & restricted & $\begin{array}{l}\text { insufficient vs. energy } \\
\text { expenditure }\end{array}$ \\
\hline External factor & peers, models & coaches, peers \\
\hline Weight loss & rapid, rather early & $\begin{array}{l}\text { progressive with increased } \\
\text { intensity of activity }\end{array}$ \\
\hline Amenorrhea & $\begin{array}{l}\text { may precede weight loss recovery } \\
\text { of menses not systematic after } \\
\text { after weight gain }\end{array}$ \\
\hline $\begin{array}{l}\text { wigns of disturbed } \\
\text { homeostasis }\end{array}$ & $\begin{array}{l}\text { reduced heart rate, blood pressure } \\
\text { and peripheral flow rate }\end{array}$ & $\begin{array}{l}\text { normal heart rate, blood pressure } \\
\text { and peripheral flow rate }\end{array}$ \\
\hline $\begin{array}{l}\text { Self-image } \\
\text { Leanness }\end{array}$ & distorted & realistic \\
\hline $\begin{array}{l}\text { Effects of estrogen } \\
\text { replacement or } \\
\text { contraceptive pill }\end{array}$ & $\begin{array}{l}\text { no significant change in general } \\
\text { wellbeing and bone density }\end{array}$ & $\begin{array}{l}\text { improvement in general wellbeing } \\
\text { and bone density }\end{array}$ \\
\hline
\end{tabular}




\section{Conclusions}

EDs, particularly AN in female adolescents, require integration of different perspectives for pathogenesis, diagnosis and management. Age and developmental stage at occurrence of the disease determine differences in short-term consequences on growth and sexual development as well as long-term outcomes. A common feature to these patients, however, is the requirement of time for improvement, accounting possibly for similar feelings and attitudes among patients, families and even care-givers: denial or minimization, opposition or control, failure or powerlessness. Therefore, clarifying and supporting can help and global appraisal is needed together with constant re-evaluation in a network of care providers. Several conditions such as adolescents involved in strenuous physical activities, are to be separated from EDs but can predispose to EDs. This should be kept in mind to propose, when appropriate, preventive measures that could hopefully reduce the frequency of true EDs that remain serious and life-threatening conditions.

\section{References}

1 Chamay-Weber C, Narring E Michaud PA: Partial eatingdisorders among adolescents: a review. J Adolesc Health 2005;37:417-427.

2 Dominé F, Berchtold A, Akré C, Michaud PA, Suris JC: Disordered eating behaviors: what about boys? J Adolesc Health 2009;44:111-117.

3 Giedd JN: The teen brain: insights from neuroimaging. J Adolesc Health 2008;42:335-343.

4 Neumark-Sztainer D, Hannan P: Weight-related behaviors among adolescent girls and boys: results from a national survey. Arch Pediatr Adolesc Med 2000;154:569-577.

- 5 Neumark-Sztainer D, Wall MM, Story M, Perry CL: Correlates of unhealthy weight-control behaviors among adolescents: implications for prevention programs. Health Psychology 2003;22:88-98.

6 DSM-IV - American Psychiatric Association: Diagnostic and Statistical Manual of Mental Disorders, ed 4. Washington, 1994.

7 International Statistical Classification of Diseases and Related Health Problems, revision 10. Version for 2007.

8 Godart N, Perdereau F, Jeammet P: Données épidé-miologiques: anorexie chez l'adolescent. J Pédiatr Puériculture 2004;17:327-330.

9 Lewinsohn PM, Hops H, Roberts RE, Seeley JR Andrews JA: Adolescent psychopathology. I. Prevalence and incidence of depression and other DSM-III-R disorders in high school students. J Abnorm Psychol 1993;102:133-144.

10 Patton GC, Selzer R Coffey C, Carlin JB, Wolfe R:Onset of adolescent eating disorders: population based cohort study over 3 years. BMJ 1999;318:765-768.

11 Santonastato P, Friederici S, Favaro A: Full and partial syndromes in eating disorders: a 1-year prospective study of risk factors among female students. Psychopathology 1999;32:50-56.

12 Rome ES, et al: Children and adolescents with eating disorders: the state of the art. Pediatrics 2003;111:98-108.

13 Ferrero FP, Rouget PC: Bulimia and weight variations in a Swiss population. Int J Eating Disord 1991;10:563-569.

14 Flament MF, Ledoux S, Jeammet P: Boulimie et autres troubles du comportement alimentaire à l'adolescence: étude épidémiologique dans une population française scolarisée. Ann Med Psychol 1993;151:635-642.

15 Klump KL, Kaye WH, Strober M: The evolving genetic foundations of eating disorders. Psychiatr Clin North Am 2001;24:215-225.

16 Home R, Van-Vactor J, Emerson S: Disturbed body image in patients with eating disorders. Am J Psychiatry 1991;148:211-215.

17 Audenaert K, et al: Decreased 5-HT2a receptor binding in patients with anorexia nervosa. J Nucl Med 2003;44:163-169.

18 Brewerton T, Jimerson D: Studies of serotonin function in anorexia nervosa. Psychiatry Res 1996;62:31-42.

19 Treasure J, Campbell I: The case for biology in the aetiology of anorexia nervosa. Psychol Med 1994; 24:3-8. 
20 Södersten P Bergh C, Ammar A: Anorexia nervosa: towards a neurobiologically based therapy. Eur J Pharmacol 2003;480:67-74.

21 Kaye W, et al: Neurobiology in anorexia nervosa: clinical implications of alterations of the function of serotonin and other neuronal systems. Int J Eating Disord 2005;37:S15-S19.

22 Stice E, Presnell K, Bearman SK: Relation of early menarche to depression, eating disorders, substance abuse, and comorbid psychopathology among adolescent girls. Dev Psychol 2001;37:608-619.

23 Leon GR, Fulkerson JA, Perry CL, Keel PK, Klump KL: Three to four year prospective evaluation of personality and behavioral risk factors for later disordered eating in adolescent girls and boys. J Youth Adolesc 1999;28:181-196.

24 Stice E, Mazotti L, Krebs M, Martin S: Predictors of adolescent dieting behaviors: a longitudinal study. Psychol Addict Behav 1998;12:195-205.

25 Wang SS, Houshyar S, Prinstein MJ: Adolescent girls' and boys' weight-related health behaviors and cognitions: associations with reputation- and preference- based peer status. Health Psychol 2006;25: 658-663.

- 26 Johnson-Sabine E, Wood K, Patton G, Mann A, Wakeling A: Abnormal eating attitudes in London schoolgirls: a prospective epidemiological study: factors associated with abnormal response on screening questionnaires. Psychol Med 1988;18:615-622.

27 Wonderlich SA, Brewerton TD, Jocic ZM, Dansky BS, Abbott DW: Relationship of childhood sexual abuse and eating disorders. J Am Acad Child Adolesc Psychiatry 1997;36:1107-1115.

28 Stice E: Risk and maintenance factors for eating pathology: a meta-analytic review. Psychol Bull 2002; $128: 825-848$

29 Rierdan J, Koff E: Depressive symptomatology among very early maturing girls. J Youth Adolesc 1991;20:415-425.

- 30 Berger U, Weitkamp K, Strauss B: Weight limits, estimations of future BMI, subjective pubertal timing and physical appearance comparisons among adolescent girls as precursors of disturbed eating behavior in a community sample. Eur Eat Disord Rev 2008;16:1-9.

31 Nichols JF, et al: Prevalence of the female athlete triad syndrome among high school athletes. Arch Pediatr Adolesc Med 2006;160:137-142.

- 32 Burns T, Crisp AH: Outcome in anorexia nervosa in males. Br J Psychiatry 1984;145:319-325.

- 33 Crisp AH, Burns T, Bhat AV: Primary anorexia nervosa in the male and female: a comparison of clinical feature and prognosis. Br J Med Psychol 1986;59: 123-132.

34 Crisp AH, et al: Anorexia nervosa in males: similarities and differences to anorexia nervosa in females. Eur Eat Disord Rev 2006;14:163-167.

35 Neumark-Sztainer D, Story M, Dixon LB, Murray DM: Adolescents engaging in unhealthy weight control behaviours: are they at risk for other health compromising behaviours? Am J Publ Health 1998; 86:952-955.

36 Warren MP, Ramos RH, Bronson EM: Exercise-associated amenorrhea: are altered leptin levels an early warning sign? Physician Sports Med 2002;30: 41-46.

- 37 Lebrethon MC, Aganina A, Fournier M, Gerard A, Parent AS, Bourguignon JP: Effects of in vivo and in vitro administration of ghrelin, leptin and neuro-peptide mediators on pulsatile gonadotrophin-releasing hormone secretion from male rat hypothalamus before and after puberty. J Neuro-endocrinol 2007;19:181-188.

- 38 Welt CK, Chan JL, Bullen J, Murphy R, Smith P DePaoli AM, Karalis A, Mantzoros CS: Recombinant human leptin in women with hypothalamic amenorrhea. N Engl J Med 2004;351:987-997.

39 Gindoff PR: Menstrual function and its relationship to stress, exercise, and body weight. Bull NY Acad Med 1989;65:774-786.

40 Hartman D, Crisp A, Rooney B, Rackow C, Atkinson R, Patel S: Bone density of women who have recovered from anorexia nervosa. Int J Eat Disord 2000;28:107-112.

41 Golden N: Eating disorders in adolescence and their sequelae. Best Pract Res Clin Obstet Gynaecol 2003; 17:57-73.

- 42 Godart NT, Flament MF, Lecrubier Y, Jeammet P: Anxiety disorders in anorexia nervosa and bulimia nervosa: co-morbidity and chronology of appearance. Eur J Psychiatry 2000;15:38-45. 
43 Anderson AE, Hedblom JE, Hubbard FA. Multidisciplinary team treatment for patients with anorexia nervosa and their families. Int J Eat Disord 2006;2:181-192.

44 de Tournemire R, Alvin P: Prise en charge soma-tique dans l'anorexie mentale: recommandations médicales. Neuropsychiatr Enfance Adolesc 2001; 49:384-392. 45 Melchior JC: Le syndrome de renutrition inappropriée. Med Hyg 1996;54:850-856.

46 Nichols JF, Rauh MJ, Lawson MJ, Ji M, Barkai HS: Prevalence of the female athlete triad syndrome among highschool athletes. Arch Pediatr Adolesc Med 2006;160:137-142.

47 Rickenlund A, et al: Effects of oral contraceptives on body composition and physical performance in female athletes. J Clin Endocrinol Metab 2004;89: 4364-4370.

48 Golden NH, Lanzkowsky L, Schebendach J, Palestro CJ, Jacobson MS, Shenker IR: The effect of oestrogen-progestatin treatment on bone mineral density in anorexia nervosa. J Pediatr Adolesc Gynecol 2002;15:135-143.

49 Munoz MT, Argente J: Anorexia nervosa in female adolescents: endocrine and bone mineral density disturbances. Eur J Endocrinol 2002;147:275-286. 